Ann. Génét. Sél. anim., I974, 6 (4), 50I-504.

NOTE

\title{
CONSÉQUENCES ÉVENTUELLES SUR LA QUALITÉ DES MATIERES GRASSES DU LAIT D'UNE SÉLECTION SUR LES CONSTITUANTS LIPIDIQUES ET LA TENEUR AZOTÉE DU LAIT DE CHEVRE
}

\author{
D. SAUVANT et P. M. FEHR \\ Laboratoire de Recherches de la Chaive de Zootechnie, I. N. R. A., \\ Institut national agronomique, Paris Grignon, \\ 16, Rue Claude-Bernard \\ 75231 Paris Cedex 05
}

\section{RÉSUMÉ}

Une étude sur les productions du lait, des matières grasses et des matières azotées, sur les taux butyreux et azoté et sur la composition en acides gras du lait de 55 chèvres a été réalisée par analyse factorielle des correspondances. Les différentes liaisons entre les caractères les plus héritables indiquent qu'une sélection sur les caractères lipidique ou azoté du lait pourrait modifier sa composition en acides gras donc, les qualités nutritionnelles et technologiques de la matière grasse du lait.

Les recherches sur l'origine des acides gras des triglycérides du lait ont le plus souvent été entreprises dans le but d'augmenter la quantité de matières grasses sécrétées par la mamelle.

Dans ce domaine, des motivations autres que purement zootechniques prennent actueilement une plus grande importance. Ainsi, la composition des matières grasses devient un élément capital à prendre en considération dans les traitements technologiques de plus en plus poussés des produits laitiers; de plus, les connaissances diététiques sur les rôles nutritionnels de certains acides gras (acides gras courts, essentiels...) et leur application en médecine contribuent à mettre en relief l'intérêt pratique d'une meilleure maîtrise des proportions relatives des divers acides gras du lait.

De nombreuses investigations ont montré que la répartition des acides gras du lait varie avec l'état physiologique de l'animal et les paramètres du milieu (SToRry, I970). Cependant, les effets de ces facteurs restent limités par les fortes variations interindividuelles de la composition des matières grasses du lait observées sur vaches (CuRRIE, I972), sur brebis (Yousef et al., 1967) ou sur chèvres (SaUvant, I973). 
Sur chèvres, ces variations individuelles nous sont apparues largement liées à la structure génétique du troupeau étudié (Sauvant, résultats non publiés). Les études récentes de RenNer et al. (1974) et d'EDWARDs et al. (1973) l'ont confirmé sur vaches laitières. En effet, ces derniers ont montré, à partir de 25 paires de jumeaux mono ou dizygotes, que l'héritabilité de la composition en acides gras des matières grasses du lait était très élevée, puisque les valeurs trouvées se situaient entre 0,85 et 0,95 pour les principaux acides hormis l'acide laurique I2: o $\left(^{1}\right)\left(h^{2}=0,64\right)$.

Bien que la méthode utilisée tende à surestimer l'héritabilité, les valeurs trouvées laissent entrevoir la possibilité de faire varier la composition des matières grasses du lait non seulement par la modification des facteurs du milieu mais aussi par sélection. Il apparaît donc, dans un premier temps essentiel d'estimer, à partir d'une étude des interrelations entre caractères héritables, les répercussions sur la composition en acides gras du lait d'une sélection sur les caractéristiques zootechniques couramment utilisées en sélection des femelles laitières : production de lait, de matières azotées et de matières grasses, taux azoté et butyreux du lait.

L'étude a porté sur 55 chèvres ( 26 Alpines, 28 Saanens, I Poitevine) du troupeau du domaine de Galle (I 8) (Génétique, I. N. R. A.).

Tous les animaux considérés ont atteint leur troisième mois de lactation. Chaque chèvre a reçu une alimentation composée de foin de dactyle-luzerne distribué ad libitum, d'un kilogramme d'ensilage vesce-blé, d'un aliment granulé composé de luzerne et de céréales distribué ad libitum et de 0,5 à 0,7 kilogramme d'un aliment complémentaire du commerce. La production de lait est estimée par pesée. Les taux butyreux et azoté du lait ont été mesurés par les méthodes Gerber et du noir-amido respectivement. La composition en acides gras des matières grasses du lait est déterminée par chromatographie en phase gazeuse selon les procédés déjà décrits (DELAGE et FEHR, 1967).

Seuls les principaux acides gras de la séquence $8:$ o à $18: 3$ ont été pris en considération. Les résultats constituent un tableau à double entrée où chacune des 55 chèvres est repérée par 23 caractères : production journalière de lait, de matières azotées, de matières grasses et des princi-

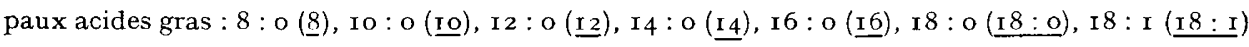
$18: 2(\underline{18: 2}), 18: 3(\underline{18: 3)}$; taux butyreux et azoté et proportions des principaux acides gras dans la matière grasse $8:$ o (8), Io : o (Io), I $2: 0$ (I 2 ), I $4: 0$ (I 4 ), I6 : o (I6), I $8:$ o (I $8:$ o), I $8:$ I (I $8: x$ ), I $8: 2(18: 2)$, I $8: 3$ (1 $8: 3)$. L'ensemble de ces données a été étudié par analyse factorielle des correspondances (BENZECRI et al., 1973). Ce type d'analyse déjà utilisé en génétique animale (LEFEBVRE et al., I97I) permet de résumer et de structurer l'information d'un tableau chiffré et d'analyser les interrelations entre ses éléments. La méthode d'interprétation des sorties graphiques a été décrite plusieurs fois (BEnzECRI $e t$ al., r973) (SAUVANT et al., 1972). Rappelons simplement qu'un axe présente un facteur principal de la dispersion des données et que les analogies de variation s'interprètent en termes de distance.

La figure I, représente la disposition des "points caractères " et des "points observations " vis-à-vis des deux principaux facteurs de variation qui expliquent respectivement 59,30 et 16,29 p. Ioo de l'inertie des données analysées. Les axes factoriels suivants n'expliquent qu'une très faible part de la dispersion des productions de lait, des matières grasses et azotées et des taux butyreax et azıté. Catte fizure constitue donc de loin la meilleure image des interrelations entre ces caractères. Le premier axe est représentatif de la dissociation bien connue entre les caractères de production et de concentration du lait. La disposition des "points acides gras " sur cet axe, indique que les animaux plus forts producteurs, ont tendance à produire des matières grasses plus riches en acides à $\mathbf{I} 8$ atomes de carbone. Le deuxième axe révèle qu'il existe, chez les animaux étudiés, indépendamment de l'aspect précédent, une discrimination entre les caractères azotés et lipidiques du lait. Sur cet axe, les chèvres dont le rapport azote/lipides du lait est élevé ont tendance à être meilleures productrices et sécrètent des matières grasses pauvres en acides gras

(1) Dans cette identification des acides gras, le premier nombre corr espondant au nombre d'atomes de carbone, le second aux doubles liaisons de la molécule considérée. 
courts et riches en acides insaturés à $\mathbf{~} 8$ atomes de carbone, en acide linoléique particulièrement et inversement pour les animaux à rapport azote/lipides faible.

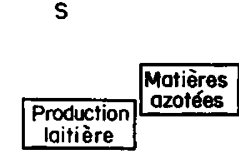

S

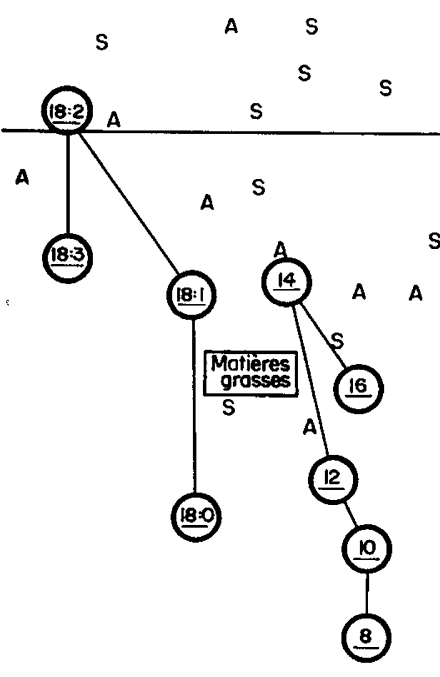

FIG. I. - Projection des animaux et des caractéristiques étudiées sur le plan des deux premiers axes factoriels
A

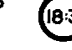

S A $\mathrm{s}$

$A$

A

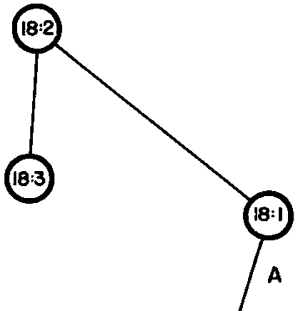

A

A

S

S

A

$A^{S}$

A

S

A

A

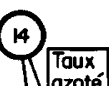

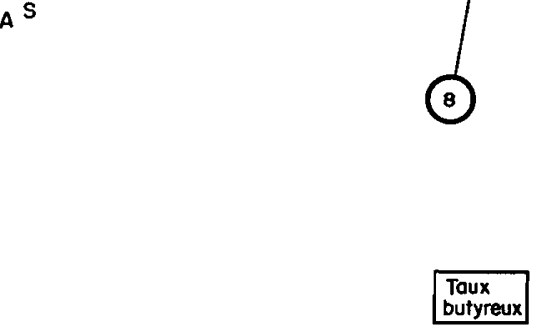

Les variations du rapport foin/aliments concentrés de la ration font apparaitre, il est vrai, une opposition entre les caractères lipidique et azoté du lait. Cependant, les résultats de nos études récentes sur chèvres, où ce rapport constituait le paramètre expérimental principal et variait donc avec une bien plus grande amplitude que dans le cas présent montrent d'une part, que l'opposition est beaucoup moins marquée entre les caractères azoté et lipidique et, d'autre part, que les modifications du spectre des acides gras sont peu comparables à celles observées sur l'axe 2 (FEHR et al., 1974). Il semblerait donc, que ce facteur de variation important de la composition et de la production du lait serait, le reflet de différences métaboliques interindividuelles. Cependant, la liaison entre la production laitière et les matières azotées qui est plus étroite que celle entre la production laitière et les matières grasses ne reflète pas les corrélations génétiques observées dans cette espèce où la production semble en effet plus opposée au taux azoté qu'au taux butyreux (RICORDEAU, I97I). Une liaison génétique de la valeur du taux butyreux positive avec la proportion des acides gras courts et négative avec celle des acides gras désaturés à $\mathbf{r} 8$ atomes de carbone a été observée par RENNER et al., (1973). Les présents résultats indiquent donc que les variations du taux azoté ont tendance à avoir l'effet inverse.

Ces premières observations demandent confirmation étant donné la réduction de la population animale étudiée et de la limitation de l'investigation à une période d'un mois de lactation environ. Cependant, les relations observées entre caractères très héritables montrent que la qualité 
nutritionnelle et technologique des matières grasses du lait risque de se modifier par une variation de sa composition en acides gras en raison de l'évolution de la composition du lait au fur et à mesure de la sélection des femelles laitières.

Reçu pour publication en novembre 1974.

\author{
SUMMARY \\ POSSIBLE CONSEQUENCES OF A SELECTION ON LIPIDIC \\ OR PROTEIC FEATURES ON THE FATTY ACID COMPOSITION OF MILK GOAT
}

The relation between milk yield, butterfat percentage and yield, protein content and yield, percentage and yield of milk fatty acids were studied with the correspondance analysis on 55 dairy goats. The different relations between the most heritable traits show that a selection on protein or fat of milk, could modify the fatty acid composition, then the nutritional and technological quality of milk fat.

\title{
RÉFÉRENCES BIBLIOGRAPHIQUES
}

BenZecri, 1973. L'analyse des données. Dunod, Paris.

CURRIE W. B., I972. Relationships between milk and milk fat composition and translactation changes in mammary gland enzyme activites in grazing cattle. Austr. J. Biol. Sci., 25, I34r-1349.

Delage J., Fehr P. M., r967. Influence des lipides alimentaires strr la sécrétion des acides gras par la mamelle de chèvre. Ann. Biol. Anim. Biochim. Biophys, 7, 437-444, 445.

Edwards R. A., King J. W. B., Yousef I. M., 1973. A note on the genetic variation in the fatty acid composition of cow milk. Anim. prod., 16, 307.

Fehr P. M., Sauvant D., I974. Influence du rapport foin/aliments concentrés du régime sur les composants de la production laitière chez la Chèvre (sous presse).

Lefebvre J., Ricordeau G., Lebeaux M. O., r97I. Correspondance entre les éléments de conformation et de production laitière chez les bovins Montbéliards. Xe Congrès Intern. Zootechn., Versailles.

Renner E., Kosmack U., I973. Genetische Zusammenhänge zwischen Fettgehalt und Fettsaürenzusammensetzung der Milch. Deutsche Milchwirtschaft, 42, x753.

Ricordeau G., I97r. Amélioration génétique de l'espèce caprine. Cours Approfondi d'Amélioration Génétique des Animaux Domestiques. I. N. A. P. G., Chaire de Zootechnie, I6, rue Claude-Bernard, Paris Ve. Ronéoté.

Sauvant D., I973. Contribution à l'étude des interactions entre les précurseurs des acides gras de la matière grasse du lait chez la Chère. Cas particulier de l'acide acétique et de l'acide stéarique. Thèse de DocteurIngénieur Université Paris VI.

Sauvant D., Fehr P. M., Rodolphe F., Tomassone R., Delage J., I973. Étude des interrelations entre les critères de production et de composition lipidique du lait de Chèvre par deux méthodes d'analyse factorielle. Ann. Biol. Anim. Biochim. Biophys., 13, 107-129.

Yousef I. M., Ashton W. M., r967. A study of the composition of Clun Forest ewe's milk. III. Ewe's milk fat : a preliminary study. J. Agric. Sci. Camb., 68, 103-107. 